\title{
Willingness to Pay for Amateur Sport and Recreation Programs
}

\author{
Bruce K. Johnson \\ Centre College \\ John C. Whitehead \\ Appalachian State University \\ Daniel S. Mason \\ University of Alberta \\ Gordon J. Walker \\ University of Alberta
}

November 2, 2006

Contact: Daniel Mason, Faculty of Physical Education \& Recreation, University of Alberta. W1-16G Van Vliet, Edmonton, Alberta, Canada T6G 2H9 dmason@ualberta.ca ph: 780-492-6822; fax: 780-492-1008 


\title{
WILLINGNESS TO PAY FOR AMATEUR SPORT AND RECREATION PROGRAMS
}

\begin{abstract}
A Contingent Valuation Method (CVM) survey in Alberta, Canada allows estimation of the household willingness to pay (WTP) for enhancements in the province's extensive sport and recreation programs. The estimated annual WTP of $\$ 18.33$ per household for small enhancements in the programs far exceeds the estimated willingness to pay of households in the United States to avoid the loss of major league sports teams, as determined in previous CVM studies. Those opposed to gambling, which helps to fund the Alberta programs, are more likely to favor using income taxes to finance expansions.

Running Head: CVM WTP for Sport and Recreation
\end{abstract}




\section{WILLINGNESS TO PAY FOR AMATEUR SPORT AND RECREATION PROGRAMS}

\section{INTRODUCTION}

In recent years, economists have begun using Contingent Valuation Method (CVM) surveys to estimate the value of public goods produced by sports and to determine what factors influence individual willingness to pay for sports public goods. They have estimated the willingness to pay for public goods resulting from the construction of a new basketball arena for a Division I power in National Collegiate Athletic Association (NCAA) basketball and from the construction of a stadium to attract a minor league baseball team to a small city (Johnson and Whitehead, 2000); the willingness to pay for public goods generated by a National Hockey League (NHL) team (Johnson, Groothuis, and Whitehead, 2001); and the willingness to pay to keep a National Football League (NFL) team and to build an arena to attract a National Basketball Association team (Johnson, Mondello, and Whitehead, forthcoming). In all cases, the willingness to pay fell far short of the subsidies required to build an arena or stadium in order to keep or attract a team. Coupled with the widely held consensus that sports stadiums and teams result in negligible effects on employment, tax revenues, and income (Baade and Dye, 1990; Baim, 1994; Coates and Humphreys, 2000; 2003; Fainstein and Stokes, 1990; Hudson, 1999; Humphreys, 2001; Rosentraub, 1997), the CVM studies reinforce the conclusion that the subsidies given to most major league teams, stadiums, and arenas do not improve economic efficiency.

The published CVM studies of sports public goods have all focused on willingness to pay for professional or major-college spectator sports, all of which are subject to monopolistic restrictions on supply. The emphasis on big-time spectator sports 
has obscured the fact that governments also subsidize many other sporting activities, including amateur athletics and recreation programs. Funding sources also extend beyond the conventional taxes posited in the hypothetical scenarios in the earlier CVM studies, including revenues from sources such as gambling. ${ }^{1}$

While amateur sporting activities do not confer major league status on their communities, they may nevertheless instill pride and unity in a community. The option to participate in a variety of sports and recreation activities may enhance the quality of life in a community even for people who choose not to exercise the option. An example would be the sporting culture associated with cities such as Melbourne, Australia. In addition, the existence of organized sports activities may produce positive externalities by keeping adolescents under adult supervision and off the street and potentially foster qualities such as sportsmanship, teamwork, and leadership. It may also improve the health and well being of participants and reduce health care costs.

This paper extends in two important dimensions the literature on the valuation of sports public goods. First, while previous studies have focused on professional spectator sports, the current paper looks at local, amateur, participatory sports and recreation programs in Canada, where opportunities to participate may provide public goods benefits to communities and the funding for which has traditionally come from public sources. Second, the paper incorporates moral norms and the Theory of Planned Behavior (TPB) into a Contingent Valuation Method (CVM) study, thus extending the methodology of earlier studies. According to the TPB, an individual's behavior depends upon his or her intention to perform a behavior which, in turn, is determined by: (a) the person's attitudes toward the behavior, e.g., is it enjoyable, or is it wise; (b) the subjective

\footnotetext{
${ }^{1}$ For the purposes of our discussion, the terms gambling and gaming will be used interchangeably.
} 
norms he or she believes significant others have concerning the behavior; (c) his or her perception of whether the behavior can be performed. Coupling TPB and CVM questions on the same survey allows estimation of the impact of moral norms on willingness to pay. This is critical where public funds are used to support programs such as amateur sport and recreation programs where the public may have a range of participatory experiences. Over the past 15 years, the TPB has been used to explain people's participation in a variety of leisure activities, including gambling (Oh and Hsu, 2001; Sheeran and Obell, 1999; Walker, Courneya, and Deng, 2006).

In addition, the source of funds to provide public subsidies may also influence opinions of their appropriateness. For example, the programs examined in this paper, located throughout the province of Alberta, Canada, are supported in part by the Alberta Lottery Fund. Because gambling carries moral baggage that income and sales taxes do not, the TPB brings added insight to the evaluation of funding for sports public goods, and to the use of gambling proceeds to fund other government programs, as well. The results below indicate that moral norms about gambling do affect willingness to pay for sports and, in comparison to previous studies, also show a much larger willingness to pay for broad-based participatory sports and recreation activities than for big-time professional spectator sports. For context, the paper first describes the Canadian amateur sport and recreation system and the role of gambling in funding those programs.

\section{CANADIAN AMATEUR SPORT SYSTEM}

The development of elite athletes for international competitions such as the Olympics is the jurisdiction of the federal government, which funds the national-level organizations that oversee specific sports (Pitter, 1996). In contrast, provincial 
governments play a much larger role in providing opportunities for non-elite athletes. Each sport and recreational activity is represented at the provincial level by a Provincial Sport Organization (PSO) or a Provincial Recreation Association (PRA). There are currently 78 PSOs and 27 PRAs in Alberta. These associations, and the amateur clubs they serve, can receive funding from gaming. They represent activities from Alpine skiing to yoga.

Funds from lotteries and other legal gaming schemes are distributed to PSOs in a number of ways. There are sixteen government ministries, of which one, the Community Development Ministry, oversees Sport and Recreation through its Community and Citizenship Services division. The Sport and Recreation branch is funded by Alberta lotteries. In addition, the Alberta Sport, Recreation Parks and Wildlife Foundation (ASRPWF) gives grants to provincial recreation and sport organizations. The foundation sponsors major games, supports the development of active lifestyles, and supports other programs (Ministry Overview, 2005). Through the ASRPWF's annual Associations Development Program Grant, PSOs receive funding derived directly from provincial gaming revenues to serve their respective memberships.

Provincial Sports Organizations and Provincial Recreation Associations sponsor thousands of activities and events throughout the province. As an example, Alberta Volleyball sponsors four leagues in Calgary and four in Edmonton. It also sponsors 23 different indoor volleyball tournaments throughout the province for different age groups and skill levels. Rugby Alberta sponsors 13 clubs in southern Alberta and another nine clubs in northern Alberta. It also organizes tournaments and sends teams to compete across Canada, including in the Canadian national championships in several different age 
groups, for both males and females. Similarly, the Alberta Amateur Baseball Council sponsors teams and leagues throughout the province. It organizes the baseball competition for the Alberta Summer Games in eight different zones for age 15 and under teams. It also sends teams in different age groups to tournaments throughout Canada, runs talent ID camps, and sponsors programs for female players.

With 105 PSOs and PRAs sponsoring activities and events for all ages and skill levels, many, perhaps most, Albertans are involved in sport and recreation as participants, spectators, coaches, volunteers, or administrators. In the survey carried out for this study, 65.7 percent of respondents said they participated in the previous 12 months as a player, coach, referee, or parent. In fiscal 2006/2007, the Alberta Lottery Fund expects to spend \$0.5 million hosting major athletic events and to provide ASRPWF with \$20.5 million (http://albertalotteryfund.ca/money_goes/).

\section{CANADIAN GAMBLING AND SPORTS AND RECREATION PROGRAMS}

The use of gaming revenues to support amateur sport and recreation programs in Alberta, while similar to other Commonwealth countries, is a relatively recent phenomenon. Gaming law in Canada has its roots in early $19^{\text {th }}$ century English statutory law, which never considered gambling illegal and never prohibited private bets between individuals. Perhaps as a result, gambling in Canada is more widely accepted than in countries with more puritanical views (Seelig and Seeling, 1998).

Canadian government revenues from gaming were negligible until the federal government created a national lottery in 1970 to help fund the 1976 Summer Olympic Games in Montreal (Campbell and Smith, 1998). By 1975 the federal government had licensed several prominent charities to operate casinos outside of the traditional summer 
period (Smith, Williams, and Pitter, 1987). Ten years later, the provinces had become the sole legal providers and regulators of gambling, operating their own gaming enterprises and licensing charities to do so (Azmier and Roach, 2000). Once provinces gained control of gaming operations, each developed its own unique approach to the expansion of gaming schemes and the allocation of profits from their operations.

In no Canadian province has gambling flourished more than in Alberta. In 2004, Alberta had 16 casinos with 6,958 slots and 353 tables, three racing centers with 624 slots and 5,992 Video Lottery Terminals (VLTs), 47 racetracks/teletheatres, 2,100 lottery ticket sites, and 6,369 charitable gaming licenses (Azmier, 2005). In fiscal 2003-04 Alberta earned $\$ 1,125.2$ billion in gaming profits. While the province has only 10 percent of the total adult population in Canada, Alberta's provincial government and charities receive 19 percent of net national gambling profits (Azmier, 2005). In 2003-04, the Alberta government collected gaming profits of $\$ 474$ per adult, highest in Canada and much higher than the national average of \$262 (Azmier, 2005).

Despite the importance of gaming in Canada, some opponents, particularly religious groups, criticize it as immoral and unproductive (Azmier and Roach, 2000). In one study, only one third of Canadian charities reported using gaming as a source of funding over the five-year period 1995-1999. Sixty-three percent of the organizations not using gambling money said that "ethical concerns" contributed to their decisions not to use it. Ninety percent of religious groups expressed ethical concerns, as did 34 percent of non-religious groups (Azmier and Roach, 2000). In addition, 58 percent of respondents in the same survey who did use gaming funds said that they would have preferred not to, 
but needed the money (Azmier and Roach, 2000). In other words, a reliance on gaming revenues has potential conflicts with the moral norms of members of these organizations.

However, "Despite the intensity of feeling expressed by some about gambling.... [a Canadian] national survey found that 63 percent agreed that gambling is acceptable.... reducing the overall tax burden, providing a source of entertainment, having important economic development benefits, and funding worthwhile causes” (Azmier and Roach, 2000, p. 4). In addition, some gaming schemes are less objectionable than others, with raffles and bingos considered "most acceptable" and slot machines and VLTs the least (Azmier and Roach, 2000, p. 15).

As a result, the use of gaming revenues has become a "necessary evil" for groups such as sport and recreation organizations in Alberta that rely on gaming revenues to survive. For example in 2001, the gaming-funded Associations Development Program Grant (ADPG) provided by the ASRPWF comprised almost $16 \%$ of the total budgets of provincial sports organizations in Alberta, with ADPG grants reaching as high as $78 \%$ of the budgets of some individual organizations. For those organizations that also rely on revenues from casinos and bingos that do not generate much additional revenue from corporate sponsorships or membership fees, virtually all of their operating budgets can be from gaming sources. Thus, it is important to determine both the WTP for sport and recreation programs for Albertans and if this is influenced by moral norms associated with gambling.

\section{SURVEY INSTRUMENT AND SAMPLE}

To determine willingness to pay (WTP) for sport and recreation in Alberta, and whether WTP is affected by gambling moral norms, a CVM survey with a TPB 
component was devised. The survey also asked about arts and cultural programs funded by provincial gaming revenues. The first section of the survey contained 14 short questions to gauge the awareness of Albertans about how the provincial government distributes its gaming revenues. The second section asked 4 questions about planned behavior and moral norms concerning provincial funding for sport and recreation programs, and 4 more questions concerning arts and culture. The third section asked seven questions about whether respondents think Alberta Lottery Fund allocations to specific programs are appropriate.

The fourth section contained the heart of the survey, the contingent valuation section. Two hypothetical scenarios were presented to respondents, one concerning the arts and one concerning sports. The sports scenario said the Alberta government was considering proposals to expand amateur sport and recreation programs, but to do so would require an increase in the provincial income tax. Respondents were first asked whether they support the idea of expanding programs with higher income taxes. The first question did not mention the degree of expansion or the size of the tax increase. If they said they support or strongly support an increase in taxes the dichotomous variable SUPPORT equals 1 . Then they were informed that the rise in income taxes would be $\$ 10$, $\$ 25$, or $\$ 50$ per year- each respondent was given just one figure-which would be enough to raise participation rates in sport and recreation programs by either 2 percent or 10 percent. Because the tax amount and participation rates were mixed and matched, six different combinations were presented to respondents. They were then asked whether they believed such an increase in participation rates could be achieved. If they responded 
very likely or somewhat likely then they accepted the scenario as plausible. If they responded unlikely, they did not accept the scenario.

Next, respondents were told to suppose that the proposal were put to a referendum. They were reminded that if the referendum passed, they would have \$TAX less to spend on other things each year. They were asked whether they would vote for or against the proposal. Next they were asked to rate how certain they were, on a 10-point scale, that they would vote for the proposal if it really were put to a referendum. If they rated their certainty at 7 or higher, then FOR takes a value of 1 . If they rated their certainty 6 or lower, their response was recoded as being against the referendum, despite their claim they would vote for it. This is done to reduce hypothetical bias.

A similar scenario about the arts was presented to respondents. Half of those surveyed were first asked about the sport and recreation programs, while half were first asked about the arts and cultural programs.

The fifth section asked questions about their activity as a participant, official, volunteer, or parent of a participant with Alberta sport and recreation programs and Alberta arts and culture programs. They were also asked to identify, from a list of 21 options, which gambling activities they had participated in within the last 12 months. The activities ranged from buying a variety of lottery tickets, to playing video lottery or slots machines, visiting casinos, to placing bets with bookies. Finally, they were asked demographic questions about their age, education, employment, income, and religion, including their religious denomination and the importance of religion in their lives.

The study instrument consisted of a Computer-Assisted Telephone Interviewing (CATI) questionnaire. It was conducted from mid April to mid June 2006. A random 
sample frame of telephone numbers for Alberta was generated, corresponding to the distribution of population in the province. One third of the numbers were from Edmonton, one third from Calgary, and one third from the mostly rural other areas of the province. The initial screening questions selected either a male or female potential respondent age 18 years or older. Based on pre-established quotas of approximately 320 respondents per area, data were collected from 967 people. In order to meet the quota requirements, 9,045 telephone numbers were called, with 5,952 of these numbers being excluded for technical reasons such as being not in service, busy, no answer, answering machine, fax machine, or business number. Another 451 numbers were excluded for noneligibility and other reasons such as being less than 18 years of age or unable to speak English. Of the 2,642 eligible numbers reached, 967 completed the survey and 1,675 people refused to participate, for an overall response rate of 36.6 percent.

Minor refinements to the instrument were made after it was pre-tested on 62 respondents. The final version of the questionnaire took participants an average of 17 minutes to complete.

\section{MORALS NORMS, SUPPORT, AND WTP}

The first stage of the analysis was to measure and examine the formation of gambling moral norms so their impact on WTP could be estimated. Moral norms are measured with three survey questions. Respondents are asked "On a scale of 1 to 5 where 1 means Strongly Disagree, 3 is neutral, and 5 is Strongly Agree, please tell me how much you agree or disagree with each of the next three statements: (1) It would go against my principles to support the Alberta Lottery Fund's use of gambling money to fund amateur sport and recreation, (2) I would feel guilty if I supported the Alberta 
Lottery Fund's use of gambling money to fund amateur sport and recreation and (3) It would be morally wrong for me to support the Alberta Lottery Fund's use of gambling money to fund amateur sport and recreation. Albertans are mostly untroubled by gambling's moral implications. More than 50 percent strongly disagree with each statement; only 16 percent to 21 percent agree slightly or strongly with each statement.

To create a moral norms variable, we sum the responses to these three questions. The scale variable MORAL is increasing in moral resistance to using gambling money to fund amateur sport and recreation. It ranges from 3 to 15, with 45 percent of the responses at the lowest level of 3. Definitions and descriptive statistics for all the variables used in the analysis appear in Tables I and II.

\section{Insert Table 1 about here}

Insert Table 2 about here

A Tobit model with the censoring threshold set at 3 is used to estimate the determinants of moral norms. Independent variables include sex, whether the respondent lives in a rural place, income, lottery participation, and importance of religion. All 926 complete cases were used. The results appear in Table III.

Insert Table 3 about here

The results show that males are less likely than females to have moral qualms about using gambling money to fund sport and recreation. Moral qualms are also negatively related to income. ${ }^{2}$

\footnotetext{
${ }^{2}$ One-hundred two missing income values are imputed from a wage regression model.
} 
The LOTTERY variable equals 1 if the respondents had spent money for one of Alberta Lottery Fund's lottery, break-open, pull-tab, or Nevada strip games during the past 12 months. Not surprisingly, people who played the lottery in the last 12 months had less moral resistance about using gambling money. Sixty-eight percent of respondents had played the lottery in the last year.

The only variable positively associated with moral qualms was religion. As the importance of religion increases, so does moral resistance to using gambling money. More than 60 percent of the sample said that religion is somewhat or very important in their lives. Twenty percent say religion is unimportant in their lives and claim no religious affiliation.

Place of residence has no effect on moral norms. Rural residents hold the same norms, ceteris paribus, as residents of Calgary and Edmonton.

Support for Using Gambling Funds and Income Taxes

The next stage of the analysis examines the impact of moral norms on support for using gambling revenue to fund sport and recreation programs. It also looks at the impact of gambling moral norms on support for the idea of using higher income taxes to expand sport and recreation programs. Probit models are used to estimate the impact of moral norms on support for using income taxes. Table IV summarizes the survey responses and shows the probit results.

Insert Table 4 about here 
Gambling appears to be a far more popular source of funding. About two-thirds of respondents support the Alberta Lottery Fund's use of gambling money to fund amateur sport and recreation while just a little more than one-fourth support the use of income taxes.

We use a probit model to determine the effects of moral norms on support for using gaming money. The dependent variable is equal to 1 if the respondent strongly or slightly supports the ALF's use of gambling money to fund amateur sport and recreation and 0 otherwise. To control for possible endogeneity bias we use the predicted value from the moral norms Tobit model in Table III as an independent variable. Since religious importance and lottery use are uncorrelated with the remaining dependent variables, they act as instrumental variables to identify the predicted moral norms variable.

The results appear in Table IV, columns A and B. The greater the moral qualms about using gambling money the less likely respondent will support using gambling funds to pay for sport and recreation programs. No other explanatory variable affects support for using lottery money. Apparently, the only factor that keeps lottery money from being universally popular as a funding source is the moral qualms some feel.

The results for the model on support of the idea of higher income taxes to expand participation rates differ markedly. The results appear in columns $\mathrm{C}$ and $\mathrm{D}$ of Table IV. Increasing moral qualms about using gambling money are associated with increasing support for income taxes to pay for sport and recreation. All other variables are significant, too. Males and Albertans outside Calgary and Edmonton are more likely to back the idea of raising income taxes. 
Ordering effects appear in the results. If respondents were asked first about sport and recreation rather than arts and culture, they were less likely to say they support higher income taxes for sports.

Willingness to Pay

With the application of standard CVM techniques, the survey data can reveal whether people are willing to pay for an enhancement of a public good. The following WTP model for sport and recreation programs in Alberta was estimated with a probit model:

$$
\mathrm{WTP}=\mathrm{f}(\text { TAX, SCOPE, FIRST, MALE, RURAL, INCOME, MORAL })
$$

where \$TAX is the annual increase in income tax the respondent was asked to pay, SCOPE is the percentage-point increase in participation, FIRST is a dummy variable indicating whether the sport and recreation scenario was presented first, and the other variables are defined as before.

Table V presents three different estimations of the WTP model. Because the percentage of yes votes was at or below 50 percent at each bid amount, we use the natural $\log$ of \$TAX to constrain estimated WTP to be positive. In Model 1, for all respondents who said they were willing to pay higher taxes in the amount asked, the dependent variable FOR was coded as 1 . This is true for all cases, even if they said they were uncertain that they would actually vote yes in a real referendum. The estimated household WTP in Model 1 is $\$ 11.22$ per year per household.

Insert Table 5 about here 
When uncertain FOR responses are counted as FOR votes, the result can be an overestimate of true willingness to pay. This CVM phenomenon is known as hypothetical bias. To adjust for hypothetical bias, Model 2 shows the results when FOR is recoded so that only those who are fairly certain they would vote FOR are recorded as 1 . The survey asked respondents to rate the certainty of their yes vote on an increasing scale of 1 to 10 . Only those who answered 7 or above were recorded as FOR. Before recoding, fifty-one percent would vote "for" if the \$TAX cost were $\$ 10,42$ percent would vote for $\$ 25$, and 36 percent would vote for with a cost of $\$ 50$. After recoding, 36 percent would vote "for" if the cost were $\$ 10,29$ percent would vote for $\$ 25$, and 26 percent would vote for with a cost of $\$ 50$. As Table V reveals, the WTP results change significantly when FOR is recoded in Model 2. The WTP is no longer significantly different from zero.

But even after recoding FOR, Model 2 may not reflect true WTP for enhanced sport and recreation programs. Forty-four percent of respondents do not accept the hypothetical scenario - they think it unlikely that the increased participation rate can be achieved with the proposed tax increase. Even supporters of increased participation won't want to pay for futile efforts to increase it.

Model 3 presents WTP estimates using only the 514 observations of those who believe the stated participation rates can be achieved with the increased funding. The dependent variable is coded in Model 3 as it is in Model 2, so that only people who are fairly certain of their yes votes are counted in favor of the proposal. The estimated WTP rises to $\$ 16.98$ and is highly significant.

Because it corrects for hypothetical bias and scenario acceptance, Model 3 is preferred. As predicted by economic theory, the probability of a yes vote falls as the tax 
amount increases. Rural residents are less willing to pay than are residents of Edmonton and Calgary. The effect of income is positive but just misses being statistically significant. Moral norms have a negative, but statistically insignificant impact. Neither the scope of the policy (i.e., the participation rate) nor the ordering of the sports and recreation scenario has an effect on the votes.

\section{BIVARIATE PROBIT ESTIMATIONS}

The results in Model 3 of Table V, while compensating for hypothetical bias and scenario acceptance, may nevertheless be biased. The willingness to pay for enhanced programs could be correlated with unobserved variables that are also correlated with support of the payment vehicle, an increase in income tax rates. The unobserved variables may be related to TPB, attitudes toward gambling and taxes, moral norms, and the like. To estimate the household willingness to pay, we use a bivariate probit model where the dependent variables are support for the idea of expanding programs and the willingness to vote for a specific tax increase. In the first equation we specify the willingness to vote for a specific tax increase. In the second we specify the support for the idea of using higher income taxes for sport and recreation programs.

$$
\begin{aligned}
& \begin{array}{l}
\pi(\mathrm{FOR}=1)=\Phi\left(\alpha_{0}+\alpha_{1} \text { STAX }+\alpha_{2} \text { SCOPE }+\alpha_{3} \text { MORAL }+\alpha_{4} \text { FIRST }+\alpha_{5}\right. \text { DEMO } \\
\left.+\varepsilon_{1}\right)
\end{array} \\
& \pi(\text { SUPPORT }=1)=\Phi\left(\beta_{0}+\beta_{1} \text { MORAL }+\beta_{2} \text { FIRST }+\beta_{3} \text { DEMO }+\varepsilon_{2}\right) \\
& \rho=\left(\varepsilon_{1}, \varepsilon_{2}\right)
\end{aligned}
$$

where $\pi($.$) is the probability function, FOR indicates a willingness to vote for the$ referendum, SUPPORT indicates support for the idea of higher income taxes, \$TAX is the increase in annual income taxes, SCOPE is the increase in participation rates, 
MORAL is the moral norms variable, FIRST indicates whether the sport scenario or the arts scenario was read to respondents first, DEMO is a vector of demographic variables, and $\Phi($.$) is the standard normal density function. A bivariate probit is appropriate if the$ correlation between error terms, $\rho$, is statistically significant. If unobservable characteristics affecting support for the idea of higher taxes are correlated with unobservable characteristics affecting the support for a particular referendum then the correlation between error terms will be statistically significant.

The results of the bivariate probit estimation appear in Table VI. They are broadly consistent with the probit results in Table V. However, the WTP estimate in Model 2 is now significantly different from zero, though still tiny. The WTP estimate for Model 3 is $\$ 18.33$, approximately the same as in the probit model and is estimated more efficiently. Because Model 3 accounts for scenario acceptance, it is the preferred model. The qualitative results are essentially the same as in the probit model in Table V.

Insert Table 6 about here

In the WTP model, gambling moral norms have no effect on willingness to pay. But in the model reported in Table IV, support for the idea of using the income tax to fund sports is positively related to moral norms. These seemingly contradictory results suggest that an increased income tax to fund amateur sports and recreation programs might receive political support from those opposed to using gambling funds. However, this support would not be enough for the referendum to pass. This is not surprising since only about a third of the sample oppose the use of gambling funds. 


\section{COMPARISON TO PREVIOUS RESULTS}

In 1997, residents of metropolitan Pittsburgh were surveyed for a CVM study (Johnson, Groothuis, and Whitehead, 2001). They were asked how much they would be willing to pay to avoid losing their NHL team, the Penguins, to another city. Compared to their annual WTP of \$5.57 per household for a high profile, major league team, the annual Alberta WTP of $\$ 18.33$ for amateur sports may seem high, especially when considering that the Pittsburgh WTP was to avoid a complete loss of the Penguins, while the Alberta figure is just for an increase in participation of a few percentage points. Several factors make the difference appear larger than it is. First, the Pittsburgh WTP is in US dollars while the Alberta WTP is in Canadian dollars. As this is being written, the Canadian dollar has been trading recently for about $\$ 0.88$ US. Second, the Pittsburgh WTP is stated in 1997 dollars. Inflation since then has decreased the value of the dollar by about 25 percent. Converting to 2006 US dollars and then converting to Canadian dollars at \$0.88 US per Canadian dollar, the US \$5.57 annual WTP for Pittsburgh becomes about \$7.91 Canadian.

After adjusting for inflation and exchange rates, the $\$ 18.33$ annual WTP for Albertan households still far exceeds the Pittsburgh WTP for the Penguins. How could WTP to avoid total loss of a high profile major league team be so far below the WTP for a small increase in the provision of amateur, participatory sport and recreation programs? Several possible explanations suggest themselves. First, the PSOs and PRAs sponsored by the Alberta Lottery Fund probably directly involve many more people than does a professional hockey team. About two-thirds of the respondents in our survey had 
participated in at least one program that is part of the sport and recreation delivery system in Alberta in the previous 12 months.

Second, the experience of playing, coaching, or organizing a sporting activity may be more intense and satisfying than is passively watching a hockey game played by strangers. Third, if you are not a hockey fan, you are unlikely to bond with others over the team, even if your friends are avid fans. With 105 sport and recreation activities sponsored by the ALF, the chances of finding an activity or event to your liking is high if you are inclined to engage in organized physical activity-you are not limited to one of the few professional sports.

The results raise the question of whether the quality of life benefits from active, participatory sports generally exceed those of passive, spectator sports. Would the large public subsidies provided to professional stadiums and teams in the United States be better spent on amateur, participatory sports? The results also raise the issue of cultural differences between Canada and the United States. Would Americans have the same WTP as Canadians for amateur sports and would Canadians have the same WTP as Americans for professional sports?

\section{AGGREGATE WTP}

According to the 2001 Canadian census, Alberta had an average of 2.6 persons per household. Alberta has experienced rapid population growth since the census and as this paper was being written its most recent officially estimated population, in 2005, stood at $3,256,816$. If average household size remains at 2.6 , this would mean there are about 1.253 million households in Alberta. The WTP estimates developed above are for household WTP. Table VII shows the net present value of aggregated household WTP, 
discounted at 4,5 , and 6 percent in perpetuity, using the annual bivariate probit estimate of WTP from Model 3.

Insert Table 7 about here

The upper bound figures in Table VII were arrived at by calculating the value of $\$ 18.33$ per year in perpetuity at three different interest rates, and then multiplying the present discounted values by the number of households in Alberta. This provides an upper bound because it assumes that the non-respondent households, had they completed the survey, would have answered them in the same way as the respondent households. The lower bound values are calculated by multiplying the survey response rate by the upper bound values. This gives a conservative aggregate WTP because it assumes that all of the non-respondents refused to answer the survey because they have no interest in and no willingness to pay for sport and recreation programs. The true discounted WTP is likely between the upper and lower bound figures given in Table VI, though it is impossible to say whether the true value is closer to the upper or lower bound.

The net present values in Table VI appear at first glance to be much larger than the discounted WTPs for professional sports teams and stadiums in the United States revealed by previous CVM studies. For instance, the 95 percent confidence interval for the discounted WTP for the Pittsburgh Penguins of the National Hockey League in 1997 was $\$ 23.5$ million to $\$ 66$ million (Johnson, Groothuis, and Whitehead, 2001). If the adjustments for inflation and exchange rates discussed above are made, the confidence interval increases to $\$ 33.4$ million to $\$ 93.7$ million in 2006 Canadian dollars. 
There are other reasons the Pittsburgh aggregate WTP is smaller than the Alberta figures. First, metropolitan Pittsburgh had only 947,500 households in 1997, compared to the 1,253,000 households in Alberta. If the Pittsburgh household WTP were multiplied by the number of households in Alberta, its aggregate WTP would increase by about a third, to a range of $\$ 44.1$ million to $\$ 123.9$ million. Second, interest rates were higher a decade ago. The annual Pittsburgh WTPs were discounted at 8 percent. Discounting the Alberta figures at 8 percent would reduce aggregate NPV by half of the 4 percent NPV and by 25 percent of the 6 percent NPV.

The WTP for the Jacksonville Jaguars revealed by a 2002 CVM survey also appears much lower at first glance (Johnson, Mondello, and Whitehead, forthcoming). The upper and lower bound aggregate WTPs for the Jaguars were \$35.8 million and $\$ 13.3$ million, discounted at 7 percent. Again, adjusting for inflation and exchange rates, discounting at a lower interest rate, and accounting for the fact the Jacksonville has only about one -third as many households as Alberta reduces the disparity in aggregate WTPs.

\section{CONCLUSIONS AND FUTURE DIRECTIONS}

The results do not allow a decomposition of WTP into use value and non-use value components, so how much of the WTP is for public goods cannot be determined. But it is clear that Albertans place a high value on their sport and recreation programs. The WTP is for only a small increase in participation rates. Although generalizing from just a few results is dangerous, the results raise the question of whether the quality of life benefits from active, participatory sports generally exceed those of passive, spectator sports. Would the large public subsidies provided to professional stadiums and teams in the United States be better spent on amateur, participatory sports? The results also raise 
the issue of cultural differences between Canada and the United States. Would Americans have the same WTP as Canadians for amateur sports and would Canadians have the same WTP as Americans for professional sports? Future research on WTP for professional sports in Canada and WTP for amateur, participatory sports in the United States could help answer these questions. 


\section{REFERENCES}

Azmier, J.J. Gambling in Canada 2005: Statistics and Context. Calgary: Canada West Foundation, 2005.

Azmier, J. J., and Roach, R. "The Ethics of Charitable Gaming: A Survey.” Gambling in Canada Research Report No. 10. December, 2000.

Baade, R., and Dye, R. "The Impact of Stadiums and Professional Sports on Metropolitan Area Development." Growth and Change, 2, 1990, 1-14.

Baim, D.V. (1994). The Sports Stadium as a Municipal Investment. Westport, CT: Greenwood Press, 1994.

Campbell, C.S., and Smith, G.J. "Canadian Gambling: Trends and Public Policy Issues." The Annals of the American Academy of Political and Social Science, 556, 1998, 22-35.

Coates, D. and Humphreys, B.R. "The Stadium Gambit and Local Economic Development.” Regulation, 23(2), 2000, 15-20.

Coates, D., and Humphreys, B.R. "Professional Sports Facilities, Franchises, and Urban Economic Development." UMBC Economics Working Paper 03-103. mimeo, 2003.

Fainstein, S., and Stokes, R. "Space for Play: The Impacts of Entertainment Development on New York City.” Economic Development Quarterly, 12, 1998, 150-65.

Hudson, I. "Bright Lights, Big City: Do Professional Sports Teams Increase Employment?" Journal of Urban Affairs, 21, 1999, 397-407.

Humphreys, B.R. "The Myth of Sports-led Economic Development.” Economic Development Commentary, 25, 2001, 34-37.

Johnson, B.K. and Whitehead, J.C. "Value of Public Goods From Sports Stadiums: The CVM Approach." Contemporary Economic Policy, 18(1), 2000, 48-58.

Johnson, B.K., Groothuis, P.A., and Whitehead, J.C. "The Value of Public Goods Generated By a Major League Team: The CVM Approach.” Journal of Sports Economics, 2(1), 2001, 6-21.

Johnson, B.K., Mondello, M.J., and Whitehead, J.C. "The Value of Public Goods Generated by a National Football League Team.” Journal of Sport Management, forthcoming. 
Oh, H., and Hsu, C.H.C. "Volitional Degrees of Gambling Behaviors." Annals of Tourism Research, 28(3), 2001, 618-637.

Pitter, R. "The State and Sport Development in Alberta: A Struggle for Public Status." Sociology of Sport Journal, 13, 1996, 31-50.

Seelig, M.Y., and Seeling, J.H. “'Place your Bets!' On Gambling, Government and Society." Canadian Public Forum, 24, 1998, 91-106.

Smith, G.J., Williams, B., and Pitter, R. "The Impact of Legalized Gambling on Alberta Amateur Sports Groups." Paper Presented at the Seventh International Conference on Gambling and Risk Taking, Reno, Nevada, August 26, 1987.

Walker, Gordon J., Courneya, Kerry S., and Deng, Jinyang. "Ethnicity, Gender, and the Theory of Planned Behavior: The Case of Playing the Lottery." Journal of Leisure Research, 38(2), 2006, 224-248. 


\section{Variable Definitions}

\section{Table I}

MORAL sum of responses to 3 questions about moral norms;

The higher the value, the greater the moral qualms

About gambling.

MALE 1 if respondent is male

RURAL 1 if respondent does not live in Calgary or Edmonton

INCOME annual income of respondent in thousands of Canadian dollars

LOTTERY 1 if respondent has bought an Alberta lottery ticket or scratch-off card in the previous 12 months.

RELIGIOUS 1 if respondent said religion is somewhat or very important in life.

SCOPE number of percentage points participation in sport and recreation programs was supposed to increase by if the hypothetical tax increase were to occur.

FIRST 1 if respondent heard the sport and recreation hypothetical scenario before the art and culture scenario

\$TAX the number of dollars by which the respondent's annual income tax would rise if the hypothetical referendum were to pass 


\section{Table II}

Descriptive Statistics

\begin{tabular}{|c|c|c|c|c|}
\hline & Mean & Std.Dev. & Minimum & Maximum \\
\hline MORAL & 5.93 & 3.65 & 3 & 15 \\
\hline MALE & 0.51 & 0.50 & 0 & 1 \\
\hline RURAL & 0.33 & 0.47 & 0 & 1 \\
\hline INCOME & 66.33 & 27.14 & 20 & 100 \\
\hline LOTTERY & 0.68 & 0.467 & 0 & 1 \\
\hline RELIGIOU & 2.49 & 1.48 & 0 & 4 \\
\hline SCOPE & 6.02 & 4.00 & 2 & 10 \\
\hline FIRST & 0.49 & 0.50 & 0 & 1 \\
\hline \$TAX & 28.27 & 16.5 & 10 & 50 \\
\hline
\end{tabular}




\section{Table III}

Tobit Model: Determinants of Moral Norms

$\begin{array}{lcc} & \text { Coeff. } & \text { t-ratio } \\ \text { ONE } & 3.840 & 5.03 \\ \text { MALE } & -1.164 & -2.80 \\ \text { RURAL } & -0.007 & -0.02 \\ \text { INCOME } & -0.022 & -2.91 \\ \text { LOTTERY } & -2.581 & -6.04 \\ \text { RELIGIOUS } & 0.376 & 2.68 \\ \text { Sigma } & 5.623 & 28.77 \\ \text { LL } & -1900.15 & \\ \quad & & \\ \quad \mathrm{n}=926 & & \end{array}$




\section{Table IV}

Probit Models of Support for using Lottery and Income Tax

\begin{tabular}{|c|c|c|c|c|}
\hline \multicolumn{5}{|c|}{$\begin{array}{c}\text { Support for using } \\
\text { Lottery Fund }\end{array}$} \\
\hline \multirow[t]{2}{*}{ 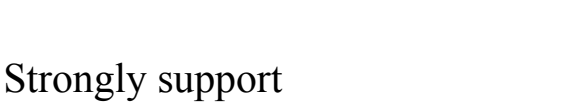 } & Freq & \multirow{2}{*}{$\begin{array}{l}\text { Percent } \\
51.62\end{array}$} & \multirow{3}{*}{$\begin{array}{c}\text { Freq } \\
64 \\
190\end{array}$} & \multirow{2}{*}{$\begin{array}{l}\text { Percent } \\
6.91\end{array}$} \\
\hline & 478 & & & \\
\hline Slightly support (support) & 132 & 14.25 & & 20.52 \\
\hline $\begin{array}{l}\text { Neither support nor do not } \\
\text { support }\end{array}$ & 121 & 13.07 & & \\
\hline Slightly do not support (oppose) & 74 & 7.99 & 243 & 26.24 \\
\hline Strongly do not support (oppose) & 121 & 13.07 & 429 & 46.33 \\
\hline & $(\mathrm{A})$ & (B) & $(\mathrm{C})$ & (D) \\
\hline & Coeff. & t-ratio & Coeff. & t-ratio \\
\hline ONE & 2.578 & 5.61 & -1.362 & -3.16 \\
\hline FIRST & & & -0.459 & -5.08 \\
\hline MALE & 0.132 & 1.15 & 0.235 & 2.29 \\
\hline RURAL & 0.042 & 0.39 & -0.186 & -1.92 \\
\hline INCOME & -0.002 & -0.88 & 0.004 & 2.33 \\
\hline MORAL & -0.252 & -4.26 & 0.104 & 1.88 \\
\hline Chi-squared & 31.26 & & 41.31 & \\
\hline
\end{tabular}




\section{TABLE V}

Probit Willingness to Pay Models

\begin{tabular}{lcccccc} 
& \multicolumn{2}{c}{ Model 1 } & \multicolumn{2}{c}{ Model 2 } & \multicolumn{2}{c}{ Model 3 } \\
& Coeff. & t-ratio & Coeff. & t-ratio & Coeff. & t-ratio \\
ONE & 0.693 & 1.53 & 0.060 & 0.13 & 1.031 & 1.71 \\
Log(\$TAX) & -0.257 & -4.04 & -0.188 & -2.84 & -0.202 & -2.35 \\
SCOPE & -0.010 & -0.94 & -0.007 & -0.63 & -0.008 & -0.57 \\
FIRST & -0.019 & -0.22 & -0.067 & -0.76 & 0.017 & 0.15 \\
MALE & -0.027 & -0.28 & 0.016 & 0.16 & 0.095 & 0.74 \\
RURAL & -0.143 & -1.60 & -0.165 & -1.75 & -0.236 & -1.96 \\
INCOME & 0.003 & 1.44 & 0.004 & 2.19 & 0.003 & 1.44 \\
MORAL & -0.019 & -0.36 & -0.024 & -0.45 & -0.105 & -1.54 \\
chi-squared & 22.84 & 20.17 & 21.54 \\
Cases & \multicolumn{2}{c}{926} & \multicolumn{2}{c}{926} & \multicolumn{2}{c}{514}
\end{tabular}

Note:

Model 1 includes all "for" votes.

Model 2 includes only those "for" votes that are fairly certain.

Model 3 includes only those fairly certain "for" votes that consider the scenario at least somewhat likely

$\begin{array}{lllllll}\text { WTP } & \$ 11.22 & 4.19 & \$ 1.42 & 1.00 & \$ 16.98 & 3.33\end{array}$

All dollar figures expressed in Canadian dollars. 


\section{TABLE VI}

Bivariate Probit Model of For Votes and Support

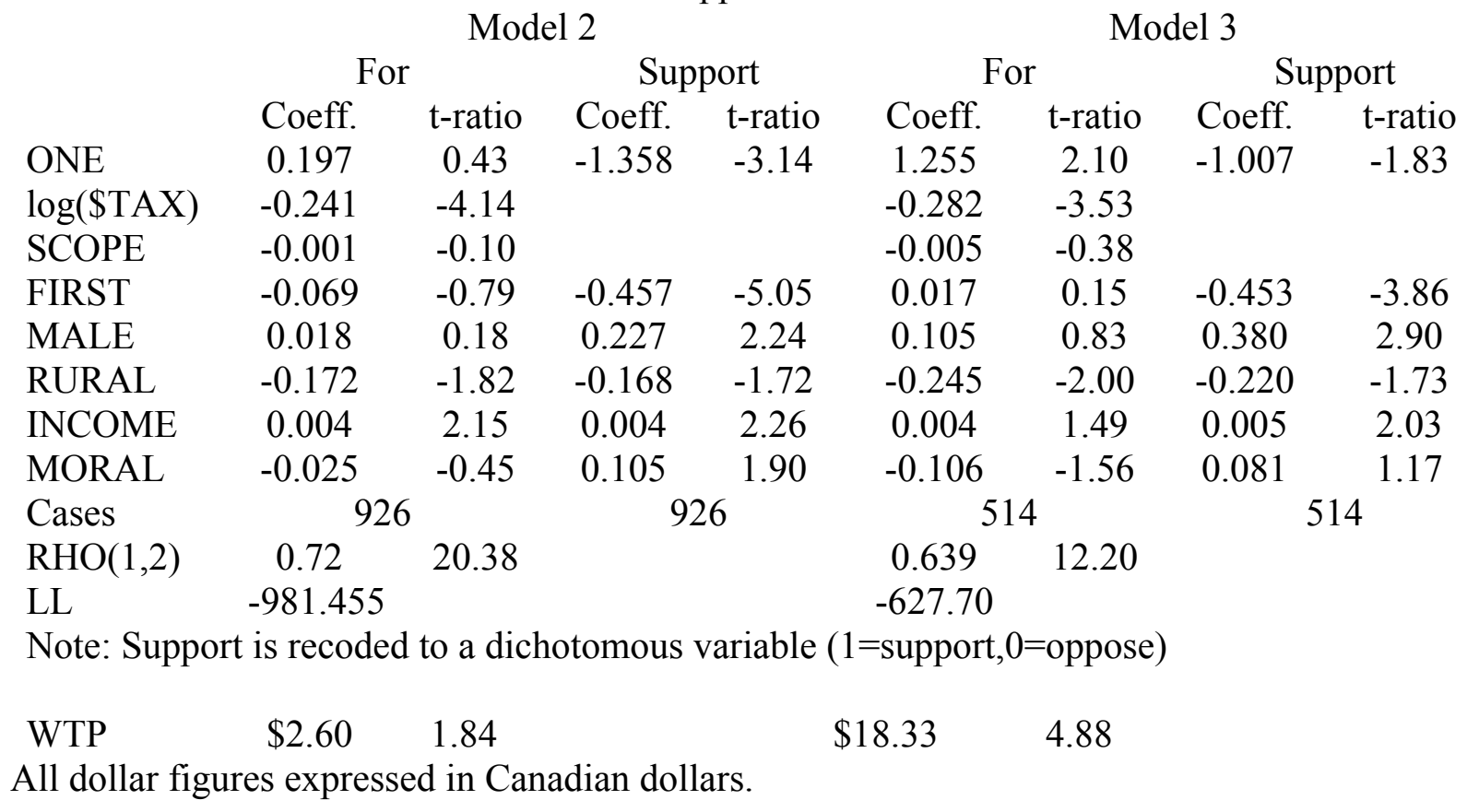




\section{Table VII}

$\begin{array}{ccc} & \text { Aggregate NPV WTP } & \\ & \text { In perpetuity, discounted at } \\ 4 \text { percent } & 5 \text { percent } & 6 \text { percent }\end{array}$

Upper Bound $\$ \$ 321,544,860 \quad \$ 257,235,888$

$\$ 214,363,240$

$\begin{array}{llll}\text { Lower Bound } \quad \$ 117,685,419 & \$ 94,148,335 & \$ 78,456,946\end{array}$

Assumptions: For the upper bound figures, annual household WTP of $\$ 18.33,1.253$ million households, 56 percent of them willing to pay because 44 percent did not accept the hypothetical scenario. All dollar figures are expressed in Canadian dollars. The lower bound figures equal the upper bound figures times 36.6 percent, the response rate for the survey. This is equivalent to assuming that the WTP for people who did not want to answer the survey was $\$ 0$. 